Service social

\title{
Public Violence in Canada, 1867-1982, par Judy M. Torrance, Montréal, McGill-Queen's University Press, 1986, 270 pages.
}

\section{François Legault}

Volume 36, numéro 1, 1987

L'informatique dans les services sociaux

URI : https://id.erudit.org/iderudit/706354ar

DOI : https://doi.org/10.7202/706354ar

Aller au sommaire du numéro

Éditeur(s)

École de service social de l'Université Laval

ISSN

1708-1734 (numérique)

Découvrir la revue

Citer ce compte rendu

Legault, F. (1987). Compte rendu de [Public Violence in Canada, 1867-1982, par Judy M. Torrance, Montréal, McGill-Queen’s University Press, 1986, 270 pages.] Service social, 36(1), 180-181. https://doi.org/10.7202/706354ar d'utilisation que vous pouvez consulter en ligne.

https://apropos.erudit.org/fr/usagers/politique-dutilisation/ 
de la réalité québécoise en matière de politique contre la discrimination en emploi.

Il est possible de lire l'ouvrage, sans en perdre le sens, en passant vite sur les analyses de cas et en sautant les annexes; mais on y perdra en approfondissement. Attention! il faut respecter l'ordre des chapitres 4, 5 et 6 de la seconde partie, pour saisir les influences américaines sur la Charte québécoise des droits et libertés (chapitre 6) et l'histoire de notre jurisprudence en la matière.

Les annexes, situées en fin de chapitres, sont nombreuses (12), étoffées et variées. Elles contiennent des conventions internationales, des extraits de lois et d'ordonnances de cour, des tableaux comparatifs, etc. Introduits dans le texte, ou placés en annexe, certains tableaux illustrent la réalité de la discrimination en emploi de façon irréfutable. De quoi faire dresser les cheveux sur la tête ! Deux tableaux synthèses à consulter à tout prix, de préférence après lecture; ils contiennent, à mon avis, des éléments de base qui pourraient facilement être traduits en outils de formation (pp. 139-141 et 399-404).

Les notes bibliographiques qu'on retrouve à la fin de chacune des parties illustrent bien l'envergure de la recherche. Elles contiennent des indications précieuses. Par exemple, quand est abordée la question de l'invisibilité des conditions de travail des femmes en usine (p. 74), l'auteure fait une critique globale des études portant sur la question et elle en présente trois. Ce sont là d'excellentes pistes pour fouiller davantage un sujet plus spécialisé.

Bref, un ouvrage complet et à la fine pointe du sujet. Je douterais même qu'il existe actuellement beaucoup de contributions aussi significatives dans la littérature internationale sur cette question. Livre à la fois sérieux et vivant, il possède un contenu scientifique impressionnant, tout en demeurant collé à la réalité quotidienne et concrète des femmes en emploi ainsi qu'à leurs luttes. Passionnant à lire... à tête reposée!

Jocelyne BARNABÉ

C.L.S.C. La source,

Charlesbourg.

Public Violence in Canada, 1867-1982, par Judy M. TorranCE, Montréal, McGillQueen's University Press, 1986, 270 pages.

Cet ouvrage porte principalement sur la violence d'ordre public, c'està-dire, "un incident qui a un impact important sur la société ou une partie de celle-ci». En plus d'être un traité sur un sujet souvent inconnu et passé inaperçu par les historiens canadiens, l'œuvre présente une explication théorique de cette violence.

L'auteur commence par remettre en question le portrait d'une nation pacifique, peint par tant d'historiens et de politiciens canadiens. En utilisant des comparaisons internationales, elle parvient à nous présenter une identité plus 
juste du Canada et de son histoire. Elle fait le recensement des théories explicatives et des facteurs potentiels et l'applique aux faits qu'elle nous présente. Par ce biais, elle analyse le rôle du gouvernement dans la prévention de la violence publique.

L'auteur est d'opinion que les relations humaines et sociales, même conflictuelles, sont mieux exercées sans violence. Elle souligne l'importance de la culture comme facteur primordial dans la fréquence et la gravité de la violence, celle-ci étant, selon elle, un comportement appris. En comparant le Canada aux États-Unis, elle réussit à faire ressortir les facteurs culturels proprement canadiens qui expliquent la nature plutôt non violente du Canada (par rapport à la plupart des pays démocratiques).

Le portrait de la violence publique au Canada présenté ici repose sur quelques exemples dispersés dans l'espace et dans le temps. Cette violence comprend : des actes d'intimidation durant des élections, des attaques contre la propriété publique dans le but de manifester le mécontentement face à la conscription, des policiers faisant feu sur des manifestants, des soldats faisant de même contre une foule hostile ou pour réprimer une rébellion, des conflits entre groupes religieux ou syndicaux, du vandalisme lors d'une grève des policiers, un groupe de Dukhabors détruisant une propriété pour se rapprocher de Dieu, des bombes pour attirer l'attention à une cause politique, et le meurtre de Pierre Laporte parce que, selon l'auteur, ses ravisseurs ne savaient que faire de lui. (L'auteur se permet quelques opinions et interprétations de certains actes violents).

Puisant dans diverses théories explicatives, elle développe un guide d'évaluation de la violence publique qui repose sur huit questions: 1) Quelles sont les motivations de la personne violente? 2) Y a-t-il un déséquilibre social (démographique, migratoire, économique)? 3) D'où vient l'idée d'agir de façon violente? 4) Cette violence est-elle justifiée, et comment? 5) Est-ce une action collective (solidarité et mobilisation) ? 6) Comment l'État réagit-il à l'acte violent ? 7) Quel est le rôle du gouvernement? 8) La violence est-elle reconnue comme publique?

Cet ouvrage est bien détaillé et ses conclusions sont amplement soutenues par des faits véridiques. Il est un outil précieux pour ceux qui œuvrent dans la politique sociale, et ceux qui se soucient du rôle que peut jouer le gouvernement dans la promotion de la non-violence. Enfin, il souligne, une fois de plus, l'importance de la culture et de la socialisation dans la violence publique.

Centre de la famille,

François LEGAULT

North Bay, Ontario. 